\title{
VALUE STREAM MAPPING IN ORDERING PROCESS - A CASE OF RETAIL CHAIN
}

\author{
Milan Andrejić ${ }^{1}$, Tamara Živanović ${ }^{2}$, Milorad Kilibarda ${ }^{3}$ \\ 1,2,3 University of Belgrade, Faculty of Transport and Traffic Engineering, Vojvode Stepe 305, \\ 11000 Belgrade, Serbia
}

Received 27 January 2021; accepted 6 April 2021

\begin{abstract}
In order to survive in the market, companies must optimally use their resources. Losses are present in all types of companies regardless of the size of the company and the industrial sector. Logistics processes as labor and cost-intensive processes are the potential source of losses. On the other hand, the greatest savings can be achieved in logistics processes. In recent years, more and more companies are realizing mentioned savings. Various tools and techniques are used in the literature for solving problems in this area. One of the most frequently used is Value Stream Mapping (VSM). This is one of the lean methods that serve to visualize activities within a particular process and identify activities that do not add value. This paper investigates how this approach can be applied to improve logistics processes in the supply chain. Applications of VSM in transport, warehousing, order picking, packaging, etc. are analyzed. There is not enough research in the literature on VSM application in the ordering process. In this paper comparative analysis of the manual ordering process and automatic ordering is conducted. A case study refers to the real system - a retail chain in Serbia. The ordering process is very important because does not add value to the product, but must be realized to certain products/services be available to the customer. Results show significant savings in different activities and a total time saving of $92,31 \%$. Other positive effects are investigated and presented. One of the most important is that store managers can focus on core activities related to sales and communication with employees and consumers. The computer cannot replace the role of man in the communication process with employees and consumers, while a man will never be able to remember and manage a large amount of data at that speed and in the way that the computer can do. The results show great applicability of the proposed methodology which is usable in all companies from different industrial sectors.
\end{abstract}

Keywords: value stream mapping, ordering process, logistics, retail chain, lean, case study.

\section{Introduction}

Rapid changes in the market, more complex customer requirements, advances in technology, force global actors to effectively adapt their activities to customers through constant improvement of their processes by creating flexible systems (Vasić et al., 2020). Such rapid changes bring with them certain risks, and a large number of planned activities are not performed in a defined time, planned costs, and with a given quality. The occurrence of losses in time, material, increase in costs, customer dissatisfaction can be largely attributed to an inefficient supply chain (Kilbarda et al., 2020). For this reason, much attention has recently been paid to supply chain management. Product delivery and provision of various logistics services along the supply chain,

${ }^{1}$ Corresponding author: m.andrejic@sf.bg.ac.rs 
has become a major factor in the efficiency of the supply chain (Andrejić and Kilibarda, 2015; Andrejić and Kilibarda, 2018). The customer or end-user, who has specific needs, expects to receive products and/or services of high quality. Understanding and visualizing logistics processes and activities within the supply chain are crucial for high-quality services.

In practice, there are few methods and tools that allow the visualization of various activities along the chain, and one of them is described in this paper and it is based on the lean principle - Value Stream Mapping (VSM). VSM is a tool that helps to map and understand material and information flows. It is used to visualize the entire system and helps to identify activities that do not add value to the product (Bait et al., 2020). In this paper, VSM is analyzed in a logistics context. Recently, a lot of papers investigate the application of VSM in logistics. Abhishek and Maheshwar (2020) suggested solutions for the reduction of each type of waste in the distribution warehouse. Actions for eliminating transportation waste using the VSM in the transportation process are defined in Popescu (2018). The observed activities are shipment loading, transporting goods to destination, unloading processes, and transportation back to the base and handling the paperwork. The procurement process is also investigated in the literature (Acero et al., 2020; Jing et al., 2020). Knoll et al. (2019) defined actions for improving internal logistics in manufacturing companies with VSM and multidimensional process mining.

Possibilities of application in logistics have been explored. The aim of this paper is to develop the methodological steps of the VSM application in the ordering process. The paper deals with a specific case study on the example of a retail chain. This area has not been sufficiently researched. To the best of the authors' knowledge, there are no papers that study VSM in the processes of ordering and packaging in retail chains. The special emphasis in this paper is a comparative analysis of manual and automatic ordering process. The next section describes VSM in more detail. Term definition, types of losses, basic tools, and steps in process of application are presented in this section. The use of VSM in logistics is shown in Section 3. VSM is analyzed in transportation, warehousing, order picking, packaging, and other logistics processes. The application of VSM is described in processes of ordering and packaging in retail chains is described in the fourth section. The results show great savings and positive effects. The concluding remarks and future research directions are presented in the last section.

\section{Value Stream Mapping}

The lean approach is one of the most frequently used approaches for process improvement. This management approach is recognized for its efficiency and productivity, continuous improvement, product quality, and timely delivery to customers, as well as for its great potential, using various tools, to identify losses within the value chain. The Lean concept uses VSM to identify unnecessary losses. It is a relatively new technique that suits the needs of all production companies to develop competitive, efficient, and flexible value chains (Suarez et al., 2016).

\subsection{Term Definition}

VSM is a tool that displays key elements of a production system based on lean production regulations and indicates how 
each interaction affects others. It is based on an organizational model for production and service companies. This technique integrates logistical flows of materials and information. Observing the connection between the flow of information and materials enables the visualization of how the system works from the moment when the customer forms an order to its delivery (Suarez et al., 2016). The technique was first developed by Toyota. Process mapping or flow display aims to show how processes operate. By plotting the process on paper or using process mapping software, it is very easy to identify the basic links between activities. A key feature of VSM is that it maps both the product/ service flow as well as the information flow that drives the product/service flow. VSM allows us to view the activities that take place during the production process, the duration of each of them, both those that add value and those that do not add value to the customer but are crucial from the company's perspective. Therefore, this approach allows the identification of potential causes of losses as well as process improvements but also showing that not all processes that do not add any value can be eliminated.

Using value chain maps, information is collected and analyzed, identifying opportunities for improvement, choosing those to be considered in the design and implementation of future value chain maps. Later, the results are reviewed and the outcomes of the new map are determined. The map includes customers, suppliers, production control, inventory, processes, production method, transport equipment, etc. All this enables: making a scheme of the most suitable output process, determining the optimal batch size, removing unnecessary steps, and assigning appropriate staff to carry out the process (Suarez et al., 2016).
The value stream is always viewed from the customer's perspective. The total flow consists of several smaller processes, each of which adds value to the customer, and the value is what the customer buys. Determining value flows involves identifying all value flows for each product, group of products, or services and eliminating losses. Special attention should be paid to unnecessary steps, losses and finding ways to eliminate them. This lean tool allows a company to (Živanović, 2020):

- Examines the flow of work information in the process required to produce a product or deliver a service;

- Understand where the biggest sources of losses (activities that cannot add value) are in the course of value;

- Forms a plan for lean implementation;

- Connect different lean techniques and concepts;

- Anticipate fewer future losses;

- Develop an implementation plan for future lean activities.

VSM integrates three components: material flow, information flow and timeline. Building a VSM is often the first step in the transformation to a lean mode. VSM will enable problem identification as well as define suggestions on how to transform the process into a lean state. In other words, VSM can be used to identify where a loss occurs and where value is added. It can also help a company understand what value it actually provides to its customers (Manning and Sörlin, 2017).

\subsection{Losses in the Value Chain}

As VSM is used to reduce losses in the value chain, it is important to understand what a loss actually is and what different types 
of losses exist. Therefore, three types of operations can be distinguished in terms of their added value (Manning and Sörlin, 2017):

1. Non-value-added activities;

2. Necessary, but activities without adding value;

\section{Value-added activities.}

As mentioned before there are valuecreating activities and loss-making activities. The following seven types of losses and consequences are the most important (Table 1).

\section{Table 1}

Losses and Consequences in Lean Concept

\begin{tabular}{|c|c|}
\hline Losses & Consequences \\
\hline Overproduction & $\begin{array}{l}\text { - Creating products that cannot be placed on the market; } \\
\text { - Performing operations that are not necessary; } \\
\text { - Creating documentation that no one requires or will not use later; } \\
\text { - Poor sales estimates, i.e. demands markets; } \\
\text { - Sending directions to too many people (or vice versa); } \\
\text { - "Just in case" production. }\end{array}$ \\
\hline Standby/Delay & $\begin{array}{l}\text { - Material waiting time between operations, waiting for workers to make machines } \\
\text { available or waiting for materials (poor production planning); } \\
\text { - Waiting for data, test results, information, decisions, signatures, approvals, etc; } \\
\text { - Waiting for delivery (e.g. late raw materials, etc.). }\end{array}$ \\
\hline Transport & $\begin{array}{l}\text { - Unnecessary movement of material between operations or between storage areas; } \\
\text { - Poor communication or information flow; } \\
\text { - Communication failure, data loss, incompatibility, information unreliability. }\end{array}$ \\
\hline Excessive Processing & $\begin{array}{l}\text { - Oversized devices, poor or inaccessible technological equipment, preparation and } \\
\text { finishing time, cleaning between treatments; } \\
\text { - Too many processing processes; } \\
\text { - Pre-treatment; } \\
\text { - Bad design, i.e. product construction that requires too many processing steps (too } \\
\text { complex product). }\end{array}$ \\
\hline Inventory & - Large inventory associated with overproduction. \\
\hline Unnecessary Handling & $\begin{array}{l}\text { - Poor machine layout, unnecessary worker movement; } \\
\text { - People who have to leave their positions to get the information they need; } \\
\text { - Manual work to compensate for some lack of production. }\end{array}$ \\
\hline Waste (Damage) & $\begin{array}{l}\text { - Interruption of flow due to error, unnecessary time, cost and space for analysis and } \\
\text { elimination; } \\
\text { - Inaccurate and incomplete information. }\end{array}$ \\
\hline
\end{tabular}

Source: (Hines and Rich, 1997)

\subsection{Basic VSM Tools}

Basic tools for reducing losses in supply chains are recognized in the literature. Table 2 also shows the related tools with mapping losses and the intensity of their solving. The letter " $H$ " denotes a high level of correlation and benefits, the letter " $M$ " indicates a medium level of correlation and benefits and the letter " $L$ " indicates a low level of correlation and benefits. 
Table 2

Intensity of Solving Losses using VSM Tools

\begin{tabular}{|c|c|c|c|c|c|c|c|}
\hline \multirow[t]{2}{*}{ Losses } & \multicolumn{7}{|c|}{ Tools } \\
\hline & $\begin{array}{l}\text { Process } \\
\text { Activity } \\
\text { Mapping }\end{array}$ & $\begin{array}{c}\text { Supply Chain } \\
\text { Response } \\
\text { Matrix }\end{array}$ & $\begin{array}{c}\text { Production } \\
\text { Variety } \\
\text { Funnel }\end{array}$ & $\begin{array}{l}\text { Quality } \\
\text { Filter } \\
\text { Mapping }\end{array}$ & $\begin{array}{c}\text { Demand } \\
\text { Amplification } \\
\text { Mapping }\end{array}$ & $\begin{array}{l}\text { Decision } \\
\text { Point } \\
\text { Analysis }\end{array}$ & $\begin{array}{c}\text { Physical } \\
\text { Structure } \\
\text { (Volume/ } \\
\text { Value) }\end{array}$ \\
\hline Overproduction & $\mathrm{L}$ & M & & $\mathrm{L}$ & M & M & \\
\hline Standby/Delay & $\mathrm{H}$ & $\mathrm{H}$ & $\mathrm{L}$ & & $\mathrm{M}$ & $\mathrm{M}$ & \\
\hline Transport & $\mathrm{H}$ & & & & & & $\mathrm{L}$ \\
\hline $\begin{array}{l}\text { Excessive } \\
\text { Processing } \\
\end{array}$ & $\mathrm{H}$ & & M & $\mathrm{L}$ & & $\mathrm{L}$ & \\
\hline Inventory & M & $\mathrm{H}$ & M & & $\mathrm{H}$ & M & $\mathrm{L}$ \\
\hline $\begin{array}{c}\text { Unnecessary } \\
\text { Handling }\end{array}$ & $\mathrm{H}$ & $\mathrm{L}$ & & & & & \\
\hline Waste (Damage) & $\mathrm{L}$ & & & $\mathrm{H}$ & & & \\
\hline Overproduction & $\mathrm{L}$ & $\mathrm{L}$ & $\mathrm{M}$ & $\mathrm{L}$ & $\mathrm{H}$ & M & $\mathrm{H}$ \\
\hline
\end{tabular}

Source: (Hines and Rich, 1997)

\subsection{Basic Steps in Creating VSM}

The value stream map is a graphical representation of all steps, tasks or activities in processes, which display product or service transformation activities, as well as information flows that trigger individual processes. It is used to determine the current state of the process and create a future flow of activities. It is drawn from the moment the raw material enters until the delivery of the finished product or service to the customer. It does not have to be a final customer, but can be another company or an internal customer within the same company. These maps can be subsequently merged into one complete value flow map. Value flow mapping can serve as a good starting point for any company that wants to introduce lean, as well as for the company to understand the connection between activities and operations (Langstrand, 2016). Value flow maps are useful for the following:

- The focus is always on the customer;

- Visually provides a complete timeline of the activity flow;
- Standardization of icons representing symbols allows easy understanding;

- Allows easy value flow analysis;

- Shows the flow of information and how it affects other activities;

- Indicate where ongoing activities are added that add value to the customer and where losses occur;

- Forms the basis for an implementation plan by indicating how the entire flow should work.

The VSM can be described as four steps methodology:

1. Product family selection;

2. Creating a map of the current state;

3. Creating a map of the future state;

4. Defining and implementing an improvement plan.

Before VSM, it is important to choose a process for improvement. It is not important to map all processes because only those processes and products that create value for them are important for customers. 


\section{VSM in Logistics}

The application of VSM in logistics and supply chains has been more intensive in recent years. In this section a brief overview of the most significant applications in logistics.

\subsection{VSM in the Transportation Process}

Transportation Value Stream Map (TVSM) is a customized version of the VSM that identifies several types of transport-specific losses, to improve efficiency as a relevant measure of performance in the transportation process. The focus is on identifying and reducing losses related to the movement of transport vehicles, primarily because they are the main source of costs, low level of reliability of delivery, and pollutants in the transport operation. Losses related to each efficiency factor: availability, performance, and quality (Villarreal, 2012). Identification of losses is achieved by creating a visual map of transport starting from the main activities such as loading of the shipment, transport of goods to the destination, unloading processes, and document handling. The design of the transport network reflects the geographical conditions of distribution, the frequency, and size of the order, the differences between transit and non-transit activities, etc (Popsecu, 2018). Some of the most important losses are:

- Losses affecting availability:

o Drive breaks: prescribed breaks during the trip are considered a loss. If a legal break is made at the end of the trip or when someone else is loading/unloading, it is not a loss;

o Excessive loading time: standard time is allowed for loading and unloading of vehicles. When loading/unloading exceeds the standard time, for reasons beyond the control of the vehicle driver, then losses occur.

- Performance losses:

o Fuel loss: ideally the vehicle will be full; either by weight or volume, depending on restrictions. The loss of charge occurs when the vehicle is not fully utilized;

- Speed loss: the difference between the maximum achieved and the average speed is the loss of speed.

- Losses affecting quality:

- Losses in quality: goods damaged in transit or incorrect documentation are a quality problem that negatively affects this measure.

\subsection{VSM in Warehousing Process}

Uncertainty in supply chains increases the risk of failure to meet targets. Warehouses can absorb some of them with a large inventory level. However, these accumulations have led that warehouses become a source of losses in supply chains. However, regardless of inventory turnover, warehouses will always exist so that the company can face variations in customer demands. It is crucial to minimize steps that do not add value to the warehouse and improve speed and throughput. Since the warehouse includes many different materials and information flows, this can be achieved by using VSM. The information flow can go from customers through the information system to the workers in the warehouse. The material flow goes through various storage operations: receiving, disposal, storage, retrieval, and finally delivery (Wessman and Bärring, 2014; Abdoli et al., 2016; Novković et al., 2020). 
When VSM is applied to supply chains, warehouses are generally presented as a "black box" of inventory. This approach ignores any detailed information regarding warehouse performances. In some studies, it defines that any increase in the inventory above the determined minimum level is viewed as inefficiency. In general, lean distinguishes activities into two classes, those that add value and those that do not. Value-added activities can be defined as activities that change the physical shape or composition of a product. Due to the nature of warehousing, warehouse activities generally do not change the shape or composition of the product. However, in the warehouse, changes occur in the product packaging units. Warehousing activities can be divided into 5 units: receipt, storage, order picking, sorting, and delivery (Abdoli et al., 2016).

In the warehouse VSM process, the first of all warehouse role in the supply chain must be determined. Accordingly, each activity within a process that adds value to the product should be defined individually. Value-added activities are generally recognizable, but sometimes non-value-added activities and losses are intertwined with value-added activities, making it difficult to clearly distinguish them. Inventories as a loss in the lean concept can be warehouse loss or supply chain loss. Warehouse losses occur due to inefficiencies in the warehouse, while supply chain losses are created due to inefficiencies in supply chain planning. The level of inventory, which arises due to the inefficiency of internal processes in the warehouse is considered a warehouse loss. Internal transport between processes in the warehouse can be considered an activity without adding value. Order picking and storing goods are considered to be the longest and most expensive storage processes. However, as value-added activities are those that directly change the status of the product, order picking is classified in this group of activities (Abdoli et al., 2016).

The current state map shows how the warehouse is currently operating and serves as a basis for future changes. It must be done for one product family (usually one with the greatest potential for improvement), otherwise, the map will be very complex. The map shows material and information flow through the warehouse. At the bottom of the map, the total processing time and delivery time are calculated. The map of the current state serves as a starting point for the development of the future state. Based on it, certain possibilities for improvement can be identified, such as reduction of material handling time, increasing the reliability of an asset, reduce truck loading time, reducing the time spent checking the location of the product, reducing inventory cycle time. The use of lean concepts can lead to a significant reduction in order processing time and delivery time while improving the accuracy of inventory and order processing (Wessman and Bärring, 2014).

The special emphasis in the literature is given to VSM in the order picking process. A lot of papers in the literature deal with savings which can be achieved with certain order picking strategies. Researches are also focused on factors that affect total time such as warehouse layout, order picker routes, equipment, failures, etc. The goal of VSM is to optimize this process and to add values delivered to customers (Purba and Aisyah, 2018). 


\subsection{VSM in Packaging Process}

Packaging of goods is a process of adding value to a product. The main purpose of packaging is to protect the goods from damage, suitable for handling, storage, etc. This process can be realized in:

- Warehouse - when the warehouse is located next to the production; when it is more rational to transport the goods to the warehouse unpackaged (lower transport costs); when it is necessary to disband the logistics unit due to control (qualitative and quantitative) and other requirements (customs, processing, etc.) is then re-formed;

- Production - with a supplier or other intermediary.

As mentioned before packaging is an activity that adds value to the product, but in the packaging process, there are activities that can make losses (Manning and Sörlin, 2017). For goods packaging, it is necessary to define certain spaces within the warehouse. Accordingly, due to intensive goods flow through the warehouse, there may be a lack of space. It is often the case in production warehouses that obsolete machines are stored in the warehouse, which takes up limited space intended for product packaging, and it can be considered as a "bottleneck" of the process that limits packaging capacity and causes waiting. The allocation of packaging materials is often a bottleneck and causes double handling of materials and information and entails losses in the form of waiting and transport. This loss arises from a lack of material location information. In order to start packaging, it is necessary to approve the packaging order. For certain types of products, orders often indicate specific labeling of the packaging that needs to be prepared. It takes some time for making labels. That time can be considered a loss because during that time the product is waiting, i.e. there is no activity on it. One of the main reasons for the long execution time between individual packaging process activities is that certain tasks often receive lower priority. Completing and signing documentation related to product packaging is often not considered an essential activity and this step is skipped due to lack of time.

\section{VSM in Ordering and Packaging Processes - Case Study}

In this part of the paper, an analysis of one of the stores of a certain retail chain in Serbia will be performed. Delivery to its stores is realized over $80 \%$ centrally from the distribution center and slightly less than $20 \%$ directly from suppliers. Due to a large number of stores within the chain, the company decided to improve its ordering process by introducing an automatic ordering system. It is a tool for optimizing logistics processes by improving and automating the ordering process. In this way, the company strives to optimize in-store inventories, but also to reduce the time required to order goods, both from retail stores to DC or directly to suppliers, and from DC to suppliers. In addition to reducing the time for ordering goods, another advantage of the automatic ordering of goods is that the managers in the facilities could devote themselves to other activities. In this phase only the ordering process from retail stores to $\mathrm{DC}$ at several pilot stores is active. The store observed in this paper is located in downtown Belgrade, near residential and commercial buildings. The warehouse space in this store is small (about $18 \%$ of total space). Due to limited space, the store has a smaller range of products. In this 
section, a comparison of the ordering process during the formation of manual orders by the manager in the facility and during the formation of the order proposal through automatic ordering will be presented. The comparison will be made on the basis of data and the state of the shop before the introduction of the automatic ordering of goods and on the basis of data recorded since the beginning of the application of this tool. The analysis will describe the shortcomings that have been improved by the introduction of an automatic ordering system. All data can vary on a daily basis, such as the time required to complete the ordering process, depending on the size of the purchase order, as well as the number of items in the store due to frequent changes in the range. For that reason, the analysis was done on the basis of average values in the period of 2020 (Živanović, 2020).

\subsection{Determination of Product Family}

The process of ordering each group of products within the facility is realized in the same way. However, what is specific to each of them is the different dynamics of delivery. The dynamics of ordering also depends on the dynamics of delivery. In this case, ordering for family of products
$A$ and $B$ is realized 2 days before the day of delivery, while for family of products $\mathrm{C}$ and $\mathrm{D}$ it is realized 1 day in advance. Delivery dynamics, in accordance with the number of days in the week for delivery, can be divided into the low frequency of delivery (1-2 times a week), medium frequency of delivery (3-4 times a week), and high frequency of delivery (over 5 times a week). Accordingly, within this action there are 4 product families:

1. Product family A: items under the ambient mode, high-frequency items, medium frequency of delivery;

2. Product family B: products under the ambient mode, low-frequency items, medium frequency of delivery;

3. Product family C: items under temperature regime above 0 degrees, high frequency of delivery;

4. Product family D: items under temperature regime below 0 degrees, high frequency of delivery.

For further analysis, items from the product family A are selected. This product family participates in the total turnover of the retail facility with $64 \%$. This is also the largest set of items with share in the total number of items is $48 \%$. Table 3 shows the participation of each of the family.

Table 3

Product Family Share in Turnover and Total Number of Products

\begin{tabular}{|c|c|c|}
\hline Product Family & $\begin{array}{c}\text { Share in } \\
\text { Turnover (\%) }\end{array}$ & $\begin{array}{c}\text { Share in Total } \\
\text { Number of Products (\%) }\end{array}$ \\
\hline Product Family A & 63.9 & 48.1 \\
\hline Product Family B & 14.6 & 38.1 \\
\hline Product Family C & 20.9 & 12.6 \\
\hline Product Family D & 0.6 & 1.2 \\
\hline
\end{tabular}

Source: (Živanović, 2020) 


\subsection{Manual Ordering Process}

Manual ordering of goods takes place in a retail store, by reviewing one item at a time manually and entering the required quantity to be ordered. This process is performed by the coordinator or store manager. In the retail facility, the ordering of goods is done according to a precisely determined schedule - delivery dynamics. Ordering is realized in a local application that is used in the company only in retail outlets. This application is connected to the central server of the local application, which sends the data when forming the order further to the ERP (Enterprise resource planning). After that, the data are further transferred from the ERP to the storage server, according to which these purchase orders are approved in the warehouse and commissioned. The process of transferring information according to the formed order between the mentioned applications takes on average about 60 minutes, depending on the speed of information flow. The ordering process varies with each ordering process. It depends on the experience of the manager, the speed of data transfer, the number of items that can be ordered, etc. Figure 1 shows a map of the current situation according to the average time required to implement each activity within the ordering process.

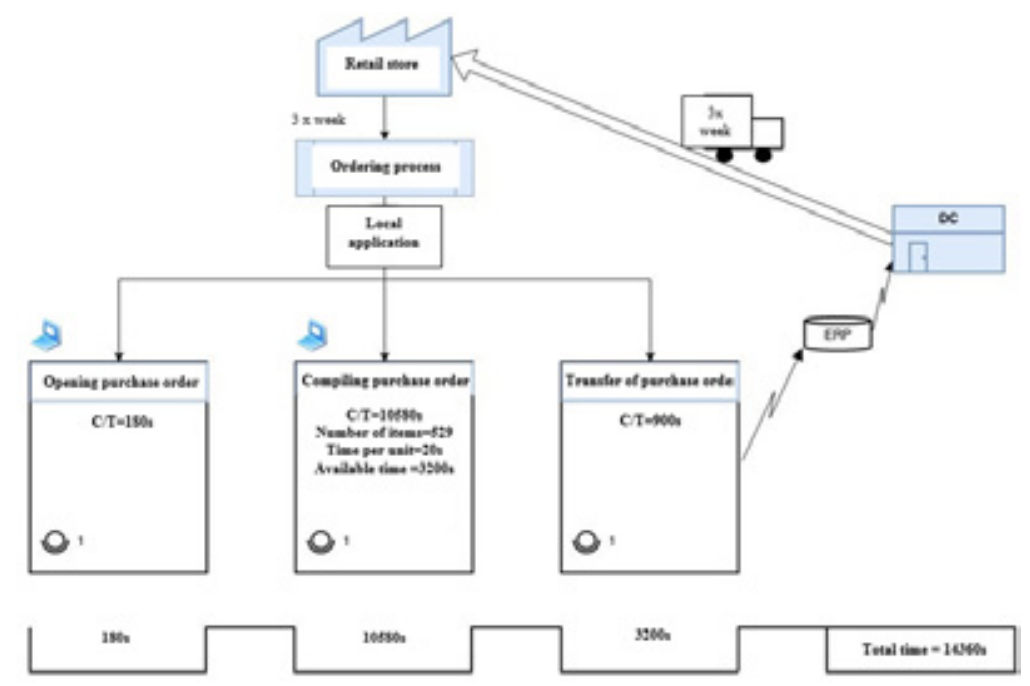

Fig. 1.

VSM in Manual Ordering Process

Source: (Živanović, 2020)

Figure 1 shows that the total time required to create a certain order is 14360 seconds, or about 4 hours. As mentioned before, there are activities that do not add value to the product but are necessary to be realized within one process. This is the case with the ordering process and the activities that are realized within it. The reason is product availability in store for customers. In addition, the speed of information flow between local applications cannot be controlled. The same situation is with the time required to access a local 
application in retail stores where ordering takes place (Živanović, 2020). The available number of items (products) to order is on average 529. The time required to review each item to make a decision on how much to order (review time) is about 20 seconds. Therefore, to form a purchase order it is necessary (Langstrand, 2016):

Cycle time $(\mathrm{C} / \mathrm{T})=529^{*} 20 \mathrm{~s}=10580 \mathrm{~s}$

Ordering can be realized in the period from $07 \mathrm{~h}-18 \mathrm{~h}$, however, since there are other product families that need to be ordered and other tasks that need to be done in that period, the available time for order realization is $2 \mathrm{~h}(7200 \mathrm{~s})$. In order to fit into the given available time of the manager, according to experience, short analysis for certain products is often skipped.

However, in order to analyze each item (product) individually with the respect of available time of 2 hours, the maximum time for determining the quantity of one product is:

Takt time $=$ Available time $/$ Number of products $=7200 / 529=13.61(\sim 14 s)$

Takt time indicates that if each item were crossed with the same level of detail, the time available to compile the purchase order would not be respected. As already mentioned, the activities within the ordering process belong to the group of activities that are necessary for the product to be available to users. However, the list of all products is bigger than the number of articles that are ordered. The loss in time could be expressed through those items that are not ordered and were considered during the review of the order list. As there are on average about 120 items on one purchase order, the time loss caused by not ordered items (529-120 $=409)$ is:

Timeloss: Cycle time $(\mathrm{C} / \mathrm{T})-$ Notordered times ${ }^{*}$ Item review time $=10580 s-409^{*} 20 s=2400 s$

This type of time loss could be classified as "over-processing". Also, in addition to the loss of time, certain shortcomings of this method of ordering goods were noticed, which are presented later in this part of the paper.

\subsubsection{Too much Information to Manage}

The order window in the local application brings all the items that are in that store. It contains data at the product level and they are item code, item name, current inventory, the number of goods to be delivered (goods on the way), daily sales in the previous week, recommendation (based on sales in the previous week), etc. When considering ordering products, the manager must pay attention to all the listed items. In addition to the information presented, the manager pays attention to the seasonality of the product, which determines the quantities to be ordered (e.g. in the summer, larger quantities of water are ordered and sold). They also must take care of important holidays such as Christmas, New Year, Easter, etc. when the turnover in the store grows (Živanović, 2020).

Within this window, it is possible to mark items with a specific color, and then sort them according to priority. Priority in the ordering process is given to items that are on sale. These are the products that have the largest share in the sale of the retail facility. In addition, there are different types of sale that last for different periods of time and that have a greater impact on increasing sales of 
a particular product. Marking items with different colors, manually in the system, is done by the manager in order to have a better overview. When it comes to promotions, one of the important information is the type of product advertising and secondary positions of promotional items or additional positions that will be highlighted in the store to attract the attention of consumers. The next priority products are those that are not on sale, but belong to the top items. They are determined by the manager according to the turnover in the previous two months. The first $10 \%$ according to the share in turnover is put on the list of top products. Among these products are products that have stable and high sales, as well as products that had increased sales in the previous two months because they were often on sale, and which have large deviations in sales. These products, as well as promotional ones, must be present in the retail store and they are given more attention when ordering. The last category of priorities is those items that are not on sale and that have a very small share in the turnover of the retail store. Given the experience of the manager, such products are very quickly reviewed and ordered (Živanović, 2020).

From the above, it can be concluded that it is necessary to manage and pay attention to various information in the ordering process. This is an extremely difficult task and the manager generally does not have the time to look at each item individually and go through all the above factors for deciding on ordering products, and as more and more items go, his concentration decreases.

\subsubsection{Large Transport Packages}

One of the main shortcomings in the process of supplying store is the large transport packages. This problem is not directly related to the ordering process, but can often be the subject of deciding whether to order a particular item or wait. As already mentioned, this is a small capacity store that has a relatively small turnover, and therefore large inventories make a big problem in space. There have been cases where the size of the transport box is disproportionate to the sale of a particular product in the store. Such products stay for several months, taking up space that could be used to store more frequent products. An additional problem is the expiration date. Mentioned products represent a monetary loss (not sold), and also generate additional logistics costs of returning to the DC. It is important to analyze the share of the sale in relation to the size of the transport unit.

\subsubsection{On Shelf Availability (OSA)}

Sales prediction is a very difficult and uncertain process. It is always possible to get into a situation where certain products are not in stocks at a retail store at some point. There are many reasons for this situation, and some of these reasons are: the return of goods, write-off of goods, theft and poor assessment of the manager, limit the number of order boxes, undefined minimum and safety stocks, etc. The reason for poor OSA may be the limit on the number of order boxes. The limit is formed as a result of overloading DC on certain days of the week. This means that DC gets into a situation that in some days of the week there are too many products for delivery, while the next day the volume of work in the warehouse drops significantly. In order for DC to be able to commission and deliver goods on time to a large number of facilities, it was necessary to introduce a restriction in order to balance the volume of work in the warehouse during the week. The 
restriction actually implies that the number of boxes that a retail store can order is defined according to previously determined demand analyzes. This further indicates that the manager is in a situation to choose which product to assign the "last" box. For some managers, it is more acceptable not to have a product on the shelf that is rarely sold than to miss the chance to sell a larger quantity of some product on sale (Živanović, 2020).

Another problem with OSA is undefined minimum and security stocks, i.e. they do not exist as such, but the manager observes them through regular stocks, taking into account certain factors. Minimum stocks are those stocks that must be available on the store shelf. Security stocks represent the quantity that should be in stocks in case of certain deviations from regular sales. As such data are not clearly defined, the manager determines what the minimum stocks will be, with great subjectivity. Product size is another factor that influences a manager's assessment of how many items can physically stay on the shelf. If it is a product of larger dimensions, only a couple of them can be set on a shelf, otherwise, if the product is small, more products can stay on the shelf. When it comes to safety stocks, managers tend to always keep larger stocks of products with high turnover even though they usually have more stable sales than products with lower turnover and larger deviation.

\subsection{Automatic Ordering Process}

As mentioned before, the main improvement of the ordering process is the automatic ordering process. This system is part of ERP and it allows automatic ordering of goods by giving proposals for order based on various factors. In other words, this system answers the questions:
- How many goods will be sold in the future? (Demand Management Process);

- How many goods need to be ordered today based on forecasts? (Order management process).

The aims of order management are placing orders on time, minimization of time spent on order proposal review, optimization of delivered quantity. On the other side aims of the demand management process are: reducing manual changers in order proposals, increasing the accuracy of demand forecasting, and inventory optimization. The automatic ordering process consists of:

- Demand forecasting calculations using appropriate statistical methods. The results are maximum forecasted demand and average (expected) forecasted demand;

- Demand calculations using current inventory, service level, minimum stocks and goods in transit, determine the demand for future periods;

- Demand optimizations based on recalculated quantities for all planned future periods.

This process is controlled by the processor of the automatic ordering system. During the night, after all the data necessary for the calculation of the order proposal have been entered into the system, the system is started and within the system operation, this data are processed. After its completion, quantities that need to be ordered appear in the system and at the same time warnings are generated that indicate to demand planners that certain products should be checked and corrected (reduce/increase quantities) if it is necessary. Table 4 compares the time required for the realization of the manual and automatic ordering process. 


\section{Table 4}

Time Required for the Realization of the Manual and Automatic Ordering Process (in seconds)

\begin{tabular}{|c|c|c|c|c|c|c|c|}
\hline Activities & $\begin{array}{c}\text { Level of } \\
\text { Observation }\end{array}$ & Measure & Quantity & $\begin{array}{c}\text { Time } \\
\text { per Unit } \\
\text { (Manual) }\end{array}$ & $\begin{array}{c}\text { Time } \\
\text { per Unit } \\
\text { (Automatic) }\end{array}$ & $\begin{array}{c}\text { Total } \\
\text { Time } \\
\text { (manual) }\end{array}$ & $\begin{array}{c}\text { Total Time } \\
\text { (Automatic) }\end{array}$ \\
\hline $\begin{array}{c}\text { Opening a } \\
\text { purchase order }\end{array}$ & $\begin{array}{c}\text { Purchase } \\
\text { order }\end{array}$ & $\begin{array}{c}\text { Number of } \\
\text { purchase order }\end{array}$ & 1 & 180 & 60 & 180 & 60 \\
\hline $\begin{array}{c}\text { Compiling a } \\
\text { purchase order }\end{array}$ & $\begin{array}{c}\text { Item } \\
\text { (product) }\end{array}$ & $\begin{array}{c}\text { Number of } \\
\text { items available } \\
\text { for ordering }\end{array}$ & 529 & 20 & 0 & 10580 & 0 \\
\hline $\begin{array}{c}\text { Quantity } \\
\text { control }\end{array}$ & $\begin{array}{c}\text { Item } \text { correction } \\
\text { of the average } \\
\text { number of } \\
\text { items on } \\
\text { purchase } \\
\text { orders }\end{array}$ & 2 & 0 & 60 & 0 & 144 \\
\hline $\begin{array}{c}\text { Transfer of } \\
\text { purchase order }\end{array}$ & $\begin{array}{c}\text { Purchase } \\
\text { order }\end{array}$ & $\begin{array}{c}\text { Number of } \\
\text { purchase order }\end{array}$ & 1 & 3600 & 900 & 3600 & 900 \\
\hline Total Time & & \multicolumn{1}{|l|}{} & & & & $\mathbf{1 4 3 6 0}$ & $\mathbf{1 1 0 4}$ \\
\hline
\end{tabular}

The table 4 shows that the largest part of the ordering time is occupied by the activity of compiling the purchase order. This activity as such does not exist in the process of automatic ordering of goods, because the system itself compiles the purchase order, which indicates a time saving of $100 \%$. Instead, a new activity appears in the automatic ordering of goods - Quantity control. On average, one purchase order contains about 120 items, of which there are warnings for about $2 \%$ of items on it. The quantity control is realized only for 2 items $(120 * 0.02=2.4)$. These two activities are very similar. In manual systems determination of quantities was done for 529 items, now the quantity control is realized only on 2 items. Automatic systems reduce the time of data transfer. The transfer of the purchase order to the storage server will be about 15 minutes with saving in time:

Savings in time of data transfer $=(3200$ $\left.15^{*} 60\right) / 3200=71.87 \%$

The great benefit of introducing such a system and switching the ordering process from the manager to the system is the focus of the manager on employees and consumers because they will have more time for core activities. Time savings in the total time required for ordering goods is:

Time savings $=(14360-1104) / 14360=92.31 \%$

Figure 2 shows a flow chart of the ordering process using an automatic goods ordering system. 


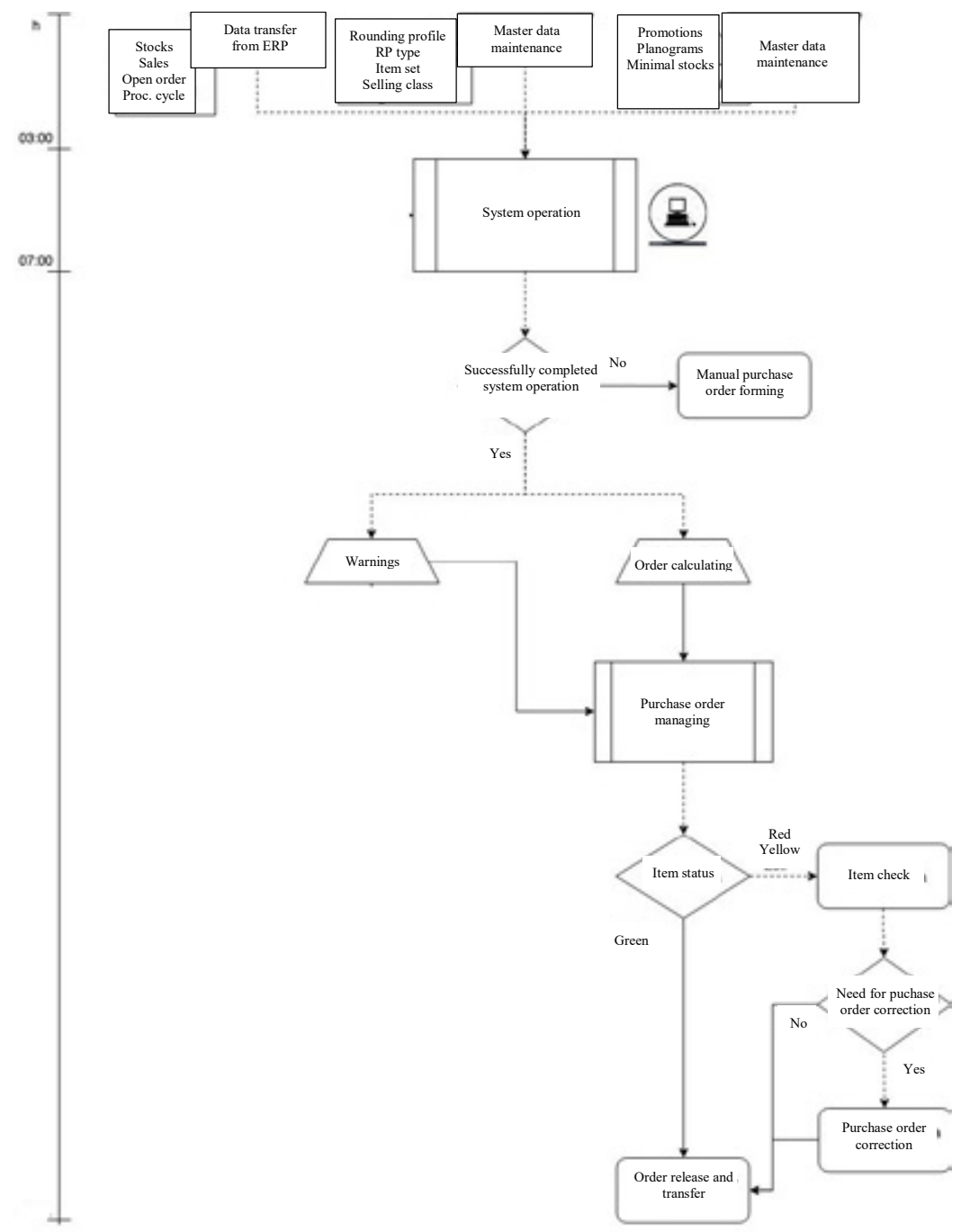

Fig. 2.

Flow Chart for Automating Ordering Process

Source: (Živanović, 2020) 


\subsubsection{Automatic Information Management System for Creating Purchase Orders}

In order for the automatic ordering process to function smoothly, it is necessary to maintain a database that includes: updating all changes in the range, planograms, tracking the history of regular and promotional sales, timely entry of future promotional activities, pre-established supply plan for stores/ warehouses, monitoring/control counting, identifying the period of sales oscillation, seasonality, monitoring the level of service in the relation warehouse - store and the level of service supplier - warehouse. Based on this given data, the background system recalculates the required quantity that will appear on the ordering proposal. Figure 3 shows the method of calculating the demand and order proposal (Živanović, 2020).

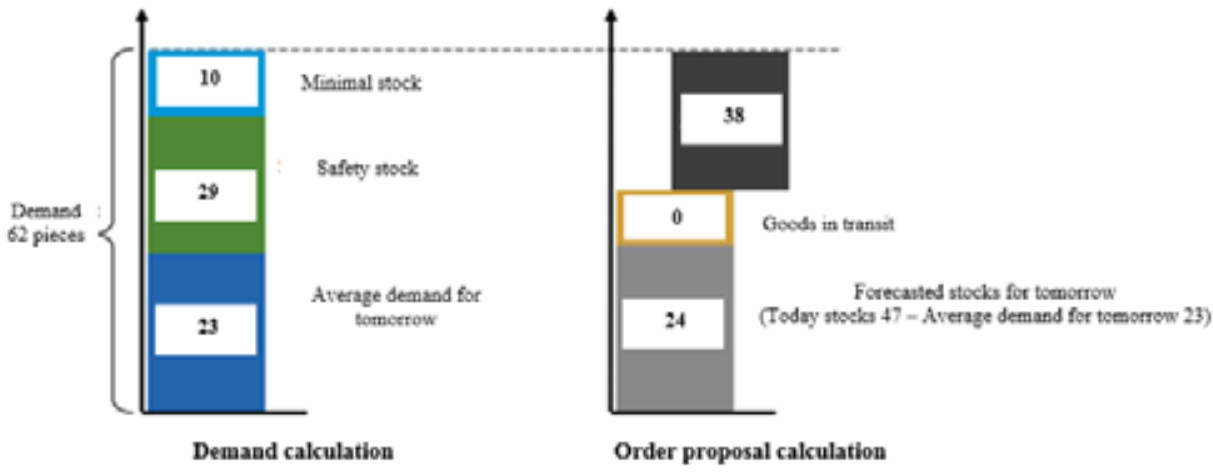

Fig. 3.

Demand Calculation and Order Proposal

Source: (Živanović, 2020)

Demand is calculated as follows (Živanović, 2020):

Minimal stocks + Safety stocks + Average demand for tomorrow $=10+29+23=62$ or

Minimal stocks + Maximum forecasted demand $=10+52=62$, where

Maximum forecasted demand $=$ Average forecasted demand + Safety stocks $=29+22=52$

When the demand is calculated, the system, based on it and the projected stocks, calculates how many goods need to be ordered if the goods in transit are taken into account.
Demand - Forecasted stocks for tomorrow + Goods in transit $=62-24+0=38$, where

Forecasted stocksfortomorrow $=$ Today stocks - Average demand for tomorrow $=47-23=24$

When the required quantity to be ordered has been calculated, rounding profiles are applied. The company has a defined issuing unit for each of its products. Some products are delivered in one piece, some in commercial packaging and some in a transport box. The projected quantities are rounded to the next whole issuing unit or to the previous smaller issuing unit. Compared to the manual method of ordering, where all the factors that affect the final quantity 
that will be ordered are taken into account by the manager, here the system does it. If all the necessary parameters are set in the system, there is a very small probability of error which was not the case in the manual system.

\subsubsection{Solving the Problem of the Transport Packages Size}

In the previous chapter, the problem of the size of transport packages was discussed. This problem can be solved in two ways: reduction of the issuing unit and the use of rounding profiles. The first method is not directly related to the system of the automatic ordering of goods, but its results may indicate the products that require a reduction of issuing units. In fact, the retail stores of this company can vary greatly according to size, turnover, consumer habits, and in one store certain items can be in stocks for only a few days, while in another it can be several months. The problem is that size of the unit for delivery from the distribution center (DC) is defined in advance in order to solve this problem in the future to negotiate with suppliers.

The second way is directly related to the way the system works. As mentioned before each item has a rounding profile, but they can change. For large transport packages of products that are difficult to sell in a particular store, such a rounding profile can be defined that the product will not be ordered without the need for it. The good thing is that they are set to not allow the number of issue units to be reduced to 0 due to the use of profiles. In other words, the system is obliged to order a product if there is even a minimal need for it (Živanović, 2020).

\subsubsection{Increased OSA}

The introduction of minimum and safety stocks reduces the probability of zero stocks. The safety stocks are recalculated by the system itself and they actually represent the difference between the actual/average demand that is predicted and the maximum demand. This completely changes the way safety stocks are observed. They represented larger quantities of stocks than needed for top items, while now larger quantities of stocks for low-consumption products with unstable sales. Also, in addition to safety stocks, another type of safety is represented by minimum stocks. The system will not allow the stocks in the store to fall below the set value.

Another problem was the limitation of the number of order boxes. However, with the introduction of an automatic ordering system, this restriction could be lifted as it would more accurately predict demand on a weekly basis. The system is programmed to monitor the historical distribution of sales of items on a daily basis, and "remembers" which days of the week are days with higher sales, and accordingly more evenly orders goods during the week. This affects the smoother logistics. Automatic ordering systems do not allow arbitrary ordering and not ordering.

\section{Conclusion}

Product delivery is one of the most important elements in the supply chain. Value-added processes make the end product or service more valuable to the end consumer. Customer satisfaction is largely affected by the delivery process. Companies are constantly 
improving in order to reduce delivery time. The aim is to deliver products quickly, with a low price and good quality. One of the most frequently used methods for time and cost-reducing is VSM. In this paper practical implementation of this method is used for the not sufficiently researched area in the literature. Ordering and e-procurement are one of the most important processes for companies from the logistics sector, but also from other sectors. This lean approach allows the company to choose the most appropriate way to improve the process by identifying the shortcomings of critical points that exist within them.

Implementation of VSM in different logistics processes (transport, warehousing, order picking, ordering, packaging, etc) is explained in this paper. Large time and costs losses are present in logistics processes. Losses affecting availability (drive breaks, excessive loading time), performance losses (fuel loss, speed loss), and losses in quality are the most frequent losses in the transportation process. The main source of losses in warehouses are inventories. In order picking process the most important problems are routes and failures of order pickers. The biggest losses in the packaging process are related to lack of space, product allocation, poor information flow and inability to monitor performance. Proposals for improvement are making a free space, the introduction of a new packaging room, the introduction of a new allocation process, the improvement of the information system, as well as the definition of key performance indicators.

Almost every application of the VSM method begins with ordering. However, this process does not add value to the product but must be realized in order for certain products/services to be available to customers. This paper presents a comparative analysis of the manual ordering process and automatic ordering using the VSM method. Automatization has become increasingly important for logistics processes in recent years. In this paper, the emphasis is on time savings with automatic ordering. Also, other benefits for the entire company are identified. For example, store managers can focus on core activities related to sale and communication with employees and consumers, which will never be able to completely replace computerized systems. On the other hand, a man will never be able to remember and manage a large amount of data at that speed and in the way that the computer can do.

In this paper, the analysis is done on one group of products in one retail store, but in the same way, can be applied in all shops for all product groups. In future research, it is necessary to expand research to the ordering process in distribution centers from suppliers. The methodological approach developed in this paper can be used in all systems in companies from different industrial sectors, regardless of the size of the company. In future research, it is necessary to develop hybrid models that combine other tools and techniques and test them on real examples.

\section{References}

Abdoli, S.; Kara, S.; Kornfeld, B. 2016. Application of dynamic value stream mapping in warehousing context, Modern Applied Science 11(1): 76-89.

Abhishek, P.G.; Maheshwar, P. 2020. Achieving Lean Warehousing Through Value Stream Mapping, South Asian Journal of Business and Management Cases 9(3): 387-401. 
Acero, R.; Torralba, M.; Pérez-Moya, R.; Pozo, J.A. 2020. Value Stream Analysis in Military Logistics: The Improvement in Order Processing Procedure, Applied Sciences 10(1): 106.

Andrejić, M.; Kilibarda, M. 2018. Risk analysis of freight forwarders' activities in organization of international commodity flows, International Journal for Traffic and Transport Engineering (IJTTE) 8(1): 45-57.

Andrejić, M.; Kilibarda, M. 2015. Distribution channels selection using PCA-DEA approach, International Journal for Traffic and Transport Engineering (IJTTE) 5(1): 74-81.

Bait, S.; Di Pietro, A.; Schiraldi, M.M. 2020. Waste Reduction in Production Processes through Simulation and VSM, Sustainability 12(8): 3291.

Hines, P.; Rich, N. 1997. The seven value stream mapping tools, International Journal of Operations \& Production Management 17(1): 46-64.

Jing, S.; Hou, K.; Yan, J.; Ho, Z.P.; Han, L. 2020. Investigating the efect of value stream mapping on procurement effectiveness: a case study, Journal of Intelligent Manufacturing (in print). doi: https://doi. org/10.1007/s10845-020-01594-x.

Kilibarda, M.; Andrejić, M.; Popović, V. 2020. Research in logistics service quality: a systematic literature review, Transport 35(2): 224-235.

Knoll, D.; Reinhart, G.; Prüglmeier, M. 2019. Enabling value stream mapping for internal logistics using multidimensional process mining, Expert Systems with Applications 124: 130-142.

Langstrand, J. 2016. An introduction to value stream mapping and analysis. Linköping University, Faculty of Science \& Engineering, 28p.

Manning, J.; Sörlin, F. 2017. Value stream mapping as a basis for process improvement in the pharmaceutical industry. Master thesis, Lund University, Faculty of Engineering. 148 p.
Novković, A.; Andrejić, M.; Kilibarda, M. 2020. Performance Appraisal and Bonus Calculation for Warehouse Employees, Tehnika 70(6): 790-798.

Popescu, M. 2018. Eliminating transportation waste using the transportation value stream map, In Proceedings of the International Conference on Business Excellence, 793803.

Purba, H.H.; Aisyah, S. 2018. Productivity improvement picking order by appropriate method, value stream mapping analysis, and storage design: A case study in automotive part center, Management and Production Engineering Review 9(1):71-81.

Suarez, M.; Miguel-Davila,J.A; Vasquez, F. 2016. Supply chain value stream mapping. A new tool of operation management, International Journal of Quality \& Reliability Management 33(4): 518-534.

Vasić, N.; Kilibarda, M.; Andrejić, M.; Jović, S. 2020. Satisfaction is a function of users of logistics services in e-commerce, Technology Analysis \& Strategic Management (in print). doi: https://doi.org/10.1080/09537325.20 20.1849610 .

Villarreal, B. 2012. The transportation value stream map (TVSM), European Journal of Industrial Engineering 6(2): 216-233.

Wessman, I.; Bärring, M. 2014. Analysing the current state of a warehouse: A Framework Based on VSM, Activity Profiling and Benchmarking. Master thesis, Lund University, Faculty of Engineering, Department of Industrial Management and Logistics. 105 p.

Živanović, T. 2020. Value Stream Mapping in logistics processes. Master thesis, University of Belgrade, Faculty of Transport and Traffic Engineering. 85 p. 